\section{DIGITAL COMMONS \\ @ UNIVERSITY OF SOUTH FLORIDA}

\section{(Q)GER}

Journal of

Global Education and Research

June 2018

\title{
Leading like an educator: How MBTI profiles vary from the norm
}

Angela Farmer

Mississippi State University, afarmer@honors.msstate.edu

Follow this and additional works at: https://digitalcommons.usf.edu/jger

Part of the Education Commons

This Refereed Article is brought to you for free and open access by the M3 Center at the University of South Florida Sarasota-Manatee at Digital Commons @ University of South Florida. It has been accepted for inclusion in Journal of Global Education and Research by an authorized editor of Digital Commons @ University of South Florida. For more information, please contact digitalcommons@usf.edu.

\section{Recommended Citation}

Farmer, A. (2018). Leading like an educator: How MBTI profiles vary from the norm. Journal of Global Education and Research, 2(1), 60-67. https://www.doi.org/10.5038/2577-509X.2.1.1041

Corresponding Author

Angela Farmer, Mississippi State University

Revisions

Submission date: Nov. 6, 2017; 1st Revision: Feb. 2, 2018; 2nd Revision: Apr. 21, 2018; Acceptance: Jun. 20 , .2018 


\title{
Leading Like an Educator: How MBTI Profiles Vary From the Norm
}

\author{
Angela Farmer \\ Mississippi State University, United States \\ asfarmer@colled.msstate.edu
}

\begin{abstract}
This article examines the particular personality traits associated with effective, active and former educational leaders, using a sample set of Myers-Briggs personality types of educational leaders from the Southeastern and Midwestern areas of the United States who attended a conference on Educational Leadership in the fall of $2017(N=19)$. It was anticipated that the characteristics of this unique set of individuals, who have elected to work for the benefit of children through the challenging aspects of administrative constraints and oversight, will emerge as having a unique personality density, separate from that of the normal population. It is further posited that understanding how select leaders to go into fields where academic integrity, fiscal responsibility, and in loco parentis standing attract a de minimus and group of individuals, focused on improving society for the next generation. It is these characteristics, which will be fully examined and explored in order to enhance the clarity of challenges and opportunities which future generations of educational leaders can expect to encounter on their journey toward facilitating academic efficacy.
\end{abstract}

Keywords: sensing, intuition, feeling, thinking, judging, perceiving, extraversion, introversion

\section{Introduction}

Perhaps it is best to reference Aristotle in analyzing a group's personality and translating its success in that community as he spoke of wonder as the impetus to wisdom (Goodman, 2013). It is this wonder which encouraged the exploration into the subgroups of type associated with a specific subset of leaders, who as former educational leaders in Kindergarten through $12^{\text {th }}$ grade settings convened at a particular location for a conference on Educational Leadership. These educational leaders elected to share their Myers-Briggs type preferences with the group out of curiosity to discover whether their composite presented something atypical of the general population as well as out of the ordinary for even those types already ascribed to have an ease in applying leadership in a less unique setting.

The Myers-Briggs Type Inventory (MBTI) further refines Jung's theories of personality tocreate 16 types, each with four subcomponents which help identify one's type preference (Briggs Myers, McCaulley, Quenk, \& Hammer, 2009). The tool relates Jung's types relevant to people's lives. It specifically identifies four dichotomies, which collectively culminate to identify one's type. Table 1, MBTI Dichotomy Analysis, provides clarity about the differences between the four dichotomies which comprise the 4-letter type designation. 
Table 1. MBTI Dichotomy Analysis

\begin{tabular}{llll}
\hline Extraversion (E) & Introversion (I) & Sensing (S) & Intuition (N) \\
\hline Initiating & Receiving & Concrete & Abstract \\
Expressive & Contained & Realistic & Imaginative \\
Gregarious & Intimate & Practical & Conceptual \\
Active & Reflective & Experiential & Theoretical \\
Enthusiastic & Quiet & Traditional & Original \\
\hline Thinking (T) & Feeling (F) & Judging (J) & Perceiving (P) \\
\hline Logical & Empathetic & Systematic & Casual \\
Reasonable & Compassionate & Planful & Open-Ended \\
Questioning & Accomodating & Early Starting & Pressure-Prompted \\
Critical & Accepting & Scheduled & Spontaneous \\
Tough & Tender & Methodical & Emergent \\
\hline
\end{tabular}

Source: CPP (2016)

After completing a Form $M$ analysis of a series of questions which allow him to find his best fit type, the individual will then be able to see his composite as it relates to the opposite preference. Individuals usually prefer either Extraversion or Introversion. Those who prefer Extraversion typically find themselves more comfortable engaged in initiating, expressive, gregarious, active, and enthusiastic interactions. Those who prefer Introversion, conversely, are more likely to find comfort in interactions where they access information in receiving, contained, intimate, reflective, and quiet environments.

Individuals who prefer Sensing are most often more comfortable with protocols which are concrete, realistic, practical, experiential, and traditional. People who prefer intuition, on the other hand, find themselves drawn to ideas which are abstract, imaginative, conceptual, theoretical, and original. The Thinking versus Feeling facets provide oppositional preferences as well. Individuals who prefer Thinking find themselves drawn to interpreting situations using a lens which is logical, reasonable, questioning, critical, and tough. People who are better aligned with the feeling orientation find themselves more comfortable with addressing a situation with a lens which is empathetic, compassionate, accommodating, accepting, and tender.

The fourth and final facet, is Judging versus Perceiving. Individuals who approach challenges with a Judging focus are likely to see things in a systematic, planful, early starting, scheduled, and methodical lens. Those who prefer the Perceiving focus in a casual, open-ended, pressureprompted, spontaneous, and emergent manner.

Table 2, MBTI Personality Preferences, provides a visual representation of the 16 types of personality preferences identified by the Myers-Briggs Type Instrument (MBTI). It is these types which are optional types which individuals may prefer.

Table 2. MBTI Personality Preferences

\begin{tabular}{|c|c|c|c|}
\hline \multicolumn{4}{|c|}{ Four Character Idetification } \\
\hline ISTJ & ISFJ & INFJ & INTJ \\
\hline ISTP & ISFP & INFP & INTP \\
\hline ESTP & ESFP & ENFP & ENTP \\
\hline ESTJ & ESFJ & ENFJ & ENTJ \\
\hline
\end{tabular}

Source: Richmond (2008) 


\section{Literature Review}

While this study is unique as it relates to active administrative educational leaders in a professorial role, a similar study which focused on aspiring educational leaders was found (Flumerfelt, 2007). In this study from 2007, students engaged in a graduate leadership program in Oakland University were the active participants. The study involved 13 students and utilization of the Form $\mathrm{M}$ form MBTI. In this analysis, however, the students' individual types and concentration densities were not provided. Instead, the researcher elected to showcase the benefit of using the MBTI tool to explore future leaders' understanding of self and developed approaches to maximize one's type through a leadership paradigm crafted to micro-analyze the students identified type preferences.

Understanding one's alternate type dichotomy may empower select types of preferences to be better suited to certain work environments and ill suited for others. In working with a variety of unique challenges which can manifest differently from day to day, educational leaders are required to adjust to a myriad of settings and individuals regularly. They must serve and guide an elected Board of Education, most of which have limited exposure to school guidelines and policies. They must engage and guide a select group of teachers who present with very different goals and talents and resistances. Further, the educational leader is a public servant who truly is designed to serve the academic and social emotional needs of the students. Given that ultimately, the entire operation of the district which uses taxpayer funds to operate in a setting where most all citizens have either attended school in the area or have someone connected to them who is involved in some capacity in the district's efficacy in operation or outcome, it is apparent to those within the matrix that these educational leaders must maintain a flexibly rigid composure.

The imagery of the compound adjective flexibly rigid helps underpin the justification for this research as to the nature of the preferences of one who elects to pursue this line of work and is successful in this setting for an extended period of time. It is anticipated that individuals who worked for an extended career in Kindergarten through grade 12 leadership are likely to present with composite MBTI preferences outside of the realm of the normal population as well as outside of the realm of the traditional executive preference percentages identified by the organization which serves as the primary agent in training MBTI practitioners, CPP, in their "Introduction to Type and Leadership" (Richmond, 2008).

\section{Methods}

Attending a fall conference for Educational Leadership Professors who were formerly Educational Leaders in a K-12 environments in the Midwest and Southeastern regions of the United States, provided an ideal opportunity for the participants to share their Myers-Briggs

Personality Type for the purpose of research curiosity. The researcher offered the paper Form M MBTI or an on-line link for the interested attendees. Volunteers were invited to share their type either on paper or via email to the researcher's university account.

\section{Sample}

Of the 37 attendees, all of whom were exposed to the opportunity to share their type, 19 elected to complete the MBTI. It was this group of educational leaders from various universities whose personality preference data provided the impetus for the study. 


\section{Data Collection}

Based on Richmaond's Introduction to Type and Leadership (2008) there are 16 paths to leadership; however, there are specific concentrations of type personalities which aggregate in select types. For the purposes of this analysis, the researcher focused on the comparative percentages of educational leadership professors who presented with select types compared against the sample distribution of 122,864 supervisors, managers, and executive types detailed in the reference material source used (Richmond, 2008).

\section{Findings}

As presented in Table 3, Data Comparisions by Percentage, The Educational Leadership composite provided the following type frequencies. One individual self identified as ENFP while individuals self identified as ESTJ. Three individuals self identified as ENTJ with one individual self identified as ESFP. Four individuals self identified as ESFJ with one individual self identified as INTJ. One individual self identified as ISFP, one individual self identified as INFJ, and two individuals self identified as ISTJ

The sample data were then compared using percentile population densities to the normal population as well as densities within participants identified as leaders (Richmond, 2008).

Table 3: Data Comparisons by Percentage

\begin{tabular}{llll}
\hline MBTI Type & Sample Density \% & Normal Density \% & Leadership Density \% \\
\hline ENFP & 05.2 & 08.1 & 06.5 \\
ESTJ & 26.3 & 08.7 & 16.7 \\
ENTJ & 15.7 & 01.8 & 08.9 \\
ESFP & 05.2 & 08.5 & 02.6 \\
ESFJ & 21.0 & 12.3 & 04.9 \\
INTJ & 05.2 & 02.1 & 05.8 \\
ISFP & 05.2 & 08.8 & 01.9 \\
INFJ & 05.2 & 01.5 & 02.0 \\
ISTJ & 10.5 & 11.6 & 15.2 \\
ISFJ & NA & 13.8 & 03.9 \\
ISTP & NA & 05.4 & 05.0 \\
INFP & NA & 04.4 & 03.3 \\
ENFJ & NA & 02.5 & 03.7 \\
INTP & NA & 03.3 & 05.7 \\
ESTP & NA & 04.3 & 05.6 \\
ENTP & NA & 03.2 & 08.3 \\
\hline
\end{tabular}

Note. $N=19$

The empirical data analysis reveals some interesting comparisons. While ESTJ is represented in the normal population with a relatively high concentration of $8.7 \%$, it is dramatically over represented in both the anticipated, general leadership group at $16.7 \%$ and $26.3 \%$ in the sample group of educational leaders.

The next, most dominant group in the sample data, individuals with preferences for ESFJ, presented at $21 \%$. While this group shows over-representation in the sample, and an increased presence in a normal population of $12.3 \%$, it does not align with the general, leadership data, as expected where only $4.9 \%$ of leaders in a composite of all leaders are expected to prefer ESFJ. 
ENTJ preferences appear as the third most dominant group in the sample of educational leaders. Representing $15.7 \%$ of the sample, this type is expected in only $1.8 \%$ of the normal population and $8.7 \%$ of the general, leadership demographic.

The fourth most represented type preference set in the sample group was ISTJ. While the educational leaders showed a density of $10.5 \%$ for this identity, it is similarly presented in both normal populations as well as leadership ethnography with $11.6 \%$ and $15.2 \%$, respectively.

Applying an SRTT analysis, the primary analysis used by MBTI practitioners and developed by $\mathrm{CPP}$, one divides the percentages represented by the Observed data by the percentages anticipated in the Expected data, in order to realize an order of magnitude of significance within those comparisons of type. Applying the equation provides the values presented in the following SRTT Analysis of Leadership Types in Table 4.

Table 4: SRTT Analysis of Leadership Types

\begin{tabular}{llll}
\hline MBTI Type & Observed (O) & Expected $($ E) & SRTT: O/E \\
\hline ENFP & $\mathbf{0 5 . 2}$ & $\mathbf{0 8 . 1}$ & $\mathbf{0 6 . 5}$ \\
ESTJ & $\mathbf{2 6 . 3}$ & $\mathbf{0 8 . 7}$ & $\mathbf{1 6 . 7}$ \\
ENTJ & $\mathbf{1 5 . 7}$ & $\mathbf{0 1 . 8}$ & $\mathbf{0 8 . 9}$ \\
ESFP & 05.2 & 08.5 & 02.6 \\
ESFJ & 21.0 & 12.3 & 04.9 \\
INTJ & $\mathbf{0 5 . 2}$ & $\mathbf{0 2 . 1}$ & $\mathbf{0 5 . 8}$ \\
ISFP & 05.2 & 08.8 & 01.9 \\
INFJ & $\mathbf{0 5 . 2}$ & $\mathbf{0 1 . 5}$ & $\mathbf{0 2 . 0}$ \\
ISTJ & 10.5 & 11.6 & 15.2 \\
ISFJ & NA & 13.8 & 03.9 \\
ISTP & NA & 05.4 & 05.0 \\
INFP & NA & 04.4 & 03.3 \\
INTP & NA & 02.5 & 03.7 \\
ESTP & NA & 03.3 & 05.7 \\
ENTP & NA & 04.3 & 05.6 \\
ENFJ & NA & 03.2 & 08.3 \\
SUM & 99.5 & 98.9 & 22.4 \\
AVE & & & 01.3 \\
\hline NOte. $N$ & & &
\end{tabular}

Note. $N=19$

Noteworthy within this sample set appear to be the four bolded types categories which present with a density greater than two times the standard population of leaders. While ESTJ, a preference which elects Extraversion, Sensing, Thinking, and Judging was an over-represented type, appearing over three times the what one would expect within a leadership group, it was not the most over-represented type in the sample.

ENTJ, appearing to present a density of 8.72 times what would be expected in a group of leaders, definitely stands out as the largest outlier for the group of educational leaders. This increased prevalence of individuals preferring Extraversion, Intuition, Thinking, and Judging is over three times what one would expect from a group of leaders.

The final two, most over-represented types in this sample group were INTJ and INFJ, representing data concentrations of nearly two and one-half times and three and one-half times, respectively for the expected emphasis for the group of educational leaders. Perhaps by micro-analyzing the types 
for commonalities, a series of observations can be made. Of the four type presented with heightened representation, the one commonality noted was the dominance of Judging versus Perceiving types for all of these four types. Furthermore, for the personality preferences which were completely absent in the sample, five of the seven types were for individuals who relied on Perceiving over Judging.

Also noteworthy is the observation that the intensely concentrated preferences were evenly divided between individuals who preferred Extraversion and those who preferred Introversion.

Unpacking this analysis also allows one to appreciate the absence of 7 of the 16 category preferences. While the majority of these unrepresented types expected only minimal presence within a group of leaders, ENTP's anticipated density within a leadership group of $8.3 \%$ was notably absent.

In an attempt to validate the study's outcome for significance, the researcher elected to further explore the data by applying a Chi square analysis. Chi square analysis compared the MBTI types of two categories of individuals, those in leadership positions as identified by a data sample of 122,864 leaders and the subsample of educational leaders' types as presented at the conference detailed earlier. The formula for Chi Square, $X^{2}=\Sigma(O-E)^{2} / \mathrm{E}$, was used to compare two data sets to determine whether their comparisons are different enough to reject the null hypothesis or insignificant enough that the null hypothesis cannot be rejected, meaning there is no significant difference between the expected and the observed result (Fisher \& Yates, 1963). The observed data values are those provided by the researcher compared to the expected as provided by the by the Introduction to Type and Leadership's 2006 database (Richmond, 2008). Table 5 presents a graphic representation of the findings.

Table 5: Chi Square Analysis of Educational Leadership Practitioners

\begin{tabular}{lccc}
\hline Type & Obs. & Exp. & Chi Square \\
\hline ENFP & 05.2 & 08.1 & 00.05 \\
ESTJ & 26.3 & 08.7 & 01.05 \\
ENTJ & 15.7 & 01.8 & 25.16 \\
ESFP & 05.2 & 08.5 & 0.04 \\
ESFJ & 21.0 & 12.3 & 0.23 \\
INTJ & 05.2 & 02.1 & 2.91 \\
ISFP & 05.2 & 08.8 & 0.03 \\
INFJ & 05.2 & 01.5 & 8.01 \\
ISTJ & 10.5 & 11.6 & 0.07 \\
ISFJ & 00.0 & 03.9 & 00.0 \\
ISTP & 00.0 & 05.0 & 00.0 \\
INFP & 00.0 & 03.3 & 00.0 \\
INTP & 00.0 & 05.7 & 00.0 \\
ESTP & 00.0 & 05.6 & 00.0 \\
ENTP & 00.0 & 08.3 & 00.0 \\
ENFJ & 00.0 & 03.7 & 00.0 \\
SUM & 99.5 & 98.9 & 37.59 \\
\hline
\end{tabular}

Note. $N=19$ 


\section{Conclusions}

Overall, the ethnographic subgroup of educational leadership professors, who were former K-12 Educational Leaders across the Midwest and Southeastern Regions of the United States, presented some unique characteristics which appeared to distinguish it as a unique population within the composite of leadership professions. Specifically, four notable Myers-Briggs Types were identified with an increased presence over what one would anticipate within both a normal population as well as within the general, larger group identified by previous research in the Introduction to Type and Leadership (Richmond, 2008). These were ESTJ, ENTJ, ESFJ, and ISTJ. Of interest within this composite may be the one dominant facet of each of these types which identifies individuals who have a preference for Judging over Perceiving. Perhaps educators who elect to engage in the additional leadership training and coursework in order to migrate to the leadership field and stay within this high-stress environment find an inclination toward Judging over Perceiving to be better suited for career longevity.

Within the sample group, the majority of respondents preferred Extraversion over Introversion; however, the presence of the ISTJ leadership type with a density of $10.5 \%$ provides evidence that this type is certainly not without stamina. The dominant types which preferred Extraversion, specifically ESTJ, ESFJ, and ENTJ all shared the Judgment facet along with the Extraversion tendency.

Over-represented, however, was the ESTJ subgroup of educational leaders who comprised 26.3\% of the observed population. When combined with the next most represented type found in the sample demographic, ESFJ, these two accounted for $47.3 \%$ of the studied group. Dissecting this analysis, one can identify that the three shared preferences are Extraversion, Thinking, and Judging. Perhaps, these critical components comprise a fundamental personality constitutional subset which identifies individuals who are internally acclimated toward a career in educational leadership where personal interactions are critical, conflicts are evaluated analytically, and final decisions are crafted with certainty.

Furthermore, the absence of a preponderance of Perceiving types in the sample group appears to reinforce this profession's propensity toward decisional certainty, a condition which often proves to be more of a challenge for leaders who prefer Perceiving. The near equilateral division between Extraverted and Introverted tendencies which were absent within the sample group, may prove this preference dichotomy to be one which is among the most malleable within the facets as moving between these tendencies.

While the type analysis, when examined through the lens of a Chi square, proved not significantly outside of the null hypothesis. This ethnographic educational leadership subgroup within the entire leadership composite appears to present with MBTI preferences consistent with a traditional leadership paradigm and not to convey overly unique composites from what one would anticipate from a random sample of leaders from a range of settings.

\section{References}

Briggs Myers, I., McCaulley, M. H., Quenk, N. L., \& Hammer, A. L. (2009). MBTI manual (3rd ed.). Sunnyvale, CA: CPP.

CPP. (2016). MBTI Step II training slides. Sunnyvale, CA: CPP. 
Fisher, R. A., \& Yates, F. (1963). Statistical tables for biological agricultural \& medical research. (T. I. 6th., ed.) Edinburg, UK: Oliver \& Boyd.

Fisher, R. A., \& Yates, F. (n.d.). Statistical tables for biological agricultural \& medical research. (T. I. 6th., ed.) Edinburg, UK: Oliver \& Boyd.

Flumerfelt, S. (2007). Developing educational leaders: Using MBTI Form M in an online graduate program. Journal of Psychological Type, 67(11), 103-113.

Goodman, D. R. (2013). To the wonder. Journal of Religion \& Film, 17(2), 1-5.

Richmond, S. L. (2008). Introduction to type and leadership. Sunnyvale, CA: CPP. 